\title{
MANIFESTAÇÕES PATOLÓGICAS EM HABITAÇÕES POPULARES EM CONCRETO ARMADO - ESTUDO DE CASO
}

DAMASCENO, IANA

Doutoranda em Engenharia Civil

Universidade de Brasília

Pará; Brasil

iana.damasceno@gmail.com

\section{ROSA, BERNARDO}

Graduando em Engenharia Civil

Universidade Federal do Pará

Pará; Brasil

bernardosantarosa97@gmail.com

\author{
PUCCINI, PAULO \\ Graduando em Engenharia Civil \\ Faculdade Pitágoras \\ Pará; Brasil \\ paulorodolfopuccini@gmail.com
}

JASTES, GABRIEL

Graduando em Engenharia Civil

Universidade Federal do Pará

Pará; Brasil

gjastes@gmail.com

\author{
FERREIRA, MAURÍCIO \\ Professor, D Sc \\ Universidade Federal do Pará \\ Pará; Brasil \\ mpinaf@gmail.com
}

\section{RESUMO}

A pesquisa refere-se a análise das manifestações patológicas presentes no conjunto residencial habitacional, localizado no município de Marabá/PA, com cerca de 1500 (mil e quinhentas) habitações populares. Para o desenvolvimento do estudo de caso, utilizou-se a metodologia proposta por LICHTENSTEIN (1985), dividida em três etapas: levantamento das manifestações patológicas; diagnóstico e a definição da conduta a ser empregada. Durante a primeira etapa, a etapa de vistoria, foi observado que as principais ocorrências estão ligadas à deficiência no detalhamento dos projetos e incompatibilidade entre os mesmos; falhas durante a execução e utilização incorreta de materiais. Por fim, foi verificado que a prevenção e a manutenção são as formas mais eficazes contra a ocorrência de manifestações patológicas nas estruturas.

Palavras-chave: manifestação patológica, conjunto residencial habitacional e construção civil.

\section{ABSTRACT}

The research refers to the analysis of the pathological manifestations present in the residential housing complex, located in the county of Marabá/PA, with about 1500 (thousand five hundred) popular dwellings. In this sense, the LICHTENSTEIN methodology (1985) was proposed to develop the case study dividing into three stages: (1) survey of pathological manifestations; (2) diagnosis; (3) definition of the conduct to be used. During the first stage, it was observed that the main occurrences of pathological manifestations are linked to deficiency in the detailing of projects and incompatibility between them, failures during the execution and incorrect use of materials. Lastly, it was verified that prevention and maintenance are most effective ways against pathological manifestations present on structures.

Keywords: pathological manifestation, residential housing complex and civil construction. 


\section{INTRODUÇÃO}

Historicamente as camadas mais pobres da população brasileira sofreram com o descaso e ineficiência de política públicas no âmbito do direito à moradia. Nessa lógica, com a elaboração dos programas sociais inclusivos criados pelo estado, foi possível identificar essa mazela decorrente desse processo histórico. No Brasil passou-se a instituir uma política que dentre outros benefícios, incluía a necessidade de se reduzir o déficit habitacional existente no país. Entende-se por déficit habitacional: "a noção mais imediata e intuitiva de necessidade de construção de novas moradias para a solução de problemas sociais e específicos de habitação detectados em certo momento" (SECRETARIA NACIONAL DE HABITAÇÃO, 2009, p. 15).

O acesso à moradia sempre foi um tema abordado no quesito políticas públicas no Brasil. Dessa forma, ao basear-se no conhecimento obtido ao estudar esse assunto, tornou-se possível identificar a falta de competência do estado para conduzir de forma eficaz os programas habitacionais. Segundo a (FJP, 2015) o déficit habitacional brasileiro é de aproximadamente 6.186.503 milhões de domicílios, o que representa 9,3\% dos domicílios particulares permanentes e improvisados, além de representar uma das maiores mazelas sociais. Nesse sentido, as dificuldades presentes são resultados de uma elevada dependência das políticas públicas, uma vez que a população de baixa renda se encontra em $90 \%$ dessse déficit. (ANDRADE, 2012 apud PIMENTA, 2016).

Ao incentivar a moradia através da elaboração dos programas habitacionais, inúmeras construtoras passaram à optar pelo ramo de construção de casas populares. Todavia a margem de lucros obtidos pelas empresas se mostraram baixos quando comparados aos lucros de obras que envolviam incorporações imobiliárias. Com isso, houve um atrativo por parte das grandes construtoras para candidatar-se aos programas governamentais como Minha Casa Minha Vida (MCMV) que passou a contratar para obras em grande escala de unidades por contrato. (PIMENTA, 2016)

Analisando o cenário que a construção civil brasileira tem passado nos últimos anos, nota-se que os incentivos do governo federal amplificaram a expansão das construções residenciais para a população considerada de baixa renda, ao mesmo tempo em que as incorporadoras imobiliárias buscam tecnologias construtivas que reduzam custos e prazos, tornando-se importante o estudo dos sistemas de vedações verticais - parede de concreto e alvenaria estrutural - que, aparentemente, atendem as necessidades empresariais dos construtores e a demanda de domicílios por parte do governo. (BOMFIM E DUMÊT, 2013 apud PIMENTA, 2016).

Para identificar as manifestações patológicas no concreto armado, utilizou-se dos conhecimentos acumulados da área de patologias do concreto armado para uma melhor compreensão dessas manifestações. Diversas são as causas que levam uma estrutura a sofrer danos, nota-se a extrema importância do estudo dessa área da engenharia para que sejam evitadas manifestações patológicas que venham a diminuir a durabilidade das estruturas. Assim, é necessário um conhecimento de como solucionar e recuperar as estruturas que apresentam problemas no intuito de curá-las e impedir que o agente causador volte a se propagar (TRINDADE, 2015).

\section{REVISÃO BIBLIOGRÁFICA}

\subsection{Sistema Construtivo - Paredes de concreto moldadas no local}

O sistema construtivo utilizado no empreendimento foi o de paredes de concreto armado - moldados no local - que apresentam maior viabilidade executiva e consequentemente econômica para construções simultâneas e em escala. (ALVES E PEIXOTO, 2011 apud MACHADO e MARTINS, 2015). Dentre as vantagens que mais se destacam desse sistema construtivo, nota-se o menor tempo de execução com o uso de equipes reduzidas que é um dos princípios da construção enxuta, tornando-a mais racionalizada, com menores custos, facilitando a competitividade. (OLIVEIRA, 2009 apud MACHADO e MARTINS, 2015).

A execução ocorre de forma racional, tanto no sentido do uso de materiais como no de tempo. (ARÊAS, 2013). As habitações com paredes de concreto ganham em competitividade quando adotadas em larga escala, com rapidez de execução e alta repetitividade. (BORGES, 2011 apud MACHADO e MARTINS, 2015). Instituto de Pesquisas Tecnológicas (2010) apud Miotto (2015) descreve o sistema construtivo de paredes de concreto moldadas no local, sendo composto por paredes maciças de concreto, armadas com telas soldadas centralizadas entre as fôrmas e com lajes maciças de concreto também moldadas no local. 
Corsini (2012) apud Miotto (2015) em sua análise, explica que todas as paredes do sistema construtivo tem função estrutural, ou seja, não se utiliza colunas e vigas. Paredes e lajes são concretadas simultaneamente. Dessa forma, é montada a tela metálica juntamente com as instalações, e depois monta-se as formas. Segundo Misurrelli e Massuda (2009) apud Miotto (2015), a montagem do sistema de formas deve seguir a recomendação do projeto original, onde se encontra identificado a numeração e sequência de montagem das formas. Há uma sequência padrão de atividades que antecedem a montagem das formas, são elas: (1) nivelamento da laje do piso; (2) marcação de linhas de paredes no piso de apoio; (3) montagem das armaduras; (4) montagem das redes hidráulicas e elétricas, (5) posicionamento dos painéis da forma; (6) montagem dos painéis (painéis internos primeiro e painéis externos depois); (7) colocação dos caixilhos (portas e janelas); (8) colocação de grampos de fixação entre painéis; (9) posicionamento das escoras de prumo e (10) colocação de ancoragens (fechamento das fôrmas de parede). Nessa lógica, eles afirmam que a principal característica do sistema construtivo é a estrutura e vedação, assim, as paredes são concretadas todas em uma única etapa - inclusive a laje, e no interior das paredes está todo o sistema elétrico, hidráulico, caixilhos de portas e janelas embutidos após a retirada das formas.

\subsection{Patologias em estruturas de concreto armado}

O termo "patologia" é derivado do grego pathos - doença, e logia - ciência, estudo; o que significa "estudo da doença". Na construção civil a patologia é atribuida aos estudos dos danos ocorridos em edificações, sendo esses manifestados de diferentes formas, como: trincas, fissuras, eflorescências, entre outras. Por possuir diversos aspectos, recebe o nome de manifestação patológica (ARIVABENE, 2015).

De acordo com Cánovas (1988) apud Arivabene (2015), patologia é a parte da engenharia que estuda os mecanismos, os sintomas, as causas e origens dos defeitos das obras. Em alguns casos, é possível se fazer um diagnóstico das patologias apenas através da visualização. No entanto, em outros casos o problema é mais complexo, sendo necessário verificar o projeto, investigar as cargas a que foi submetida à estrutura, analisar minusiosamente a forma como foi executada a obra e, inclusive, como esta patologia reagirá diante de determinados estímulos. Dessa forma, é possível diagnosticar a causa destes problemas, corrigindo-os para não se manifestarem novamente.

Ao estudar os problemas patológicos que surgem nas edificações, nota-se que um elevado percentual dessas manifestações patológicas nas construções são originados ainda na fase de planejamento e projeto. Falhas como essas são comumente mais graves que as relacionadas à qualidade dos materiais e aos métodos construtivos. Isso se explica pela falta de investimento dos proprietários, sejam eles públicos ou privados, em projetos mais elaborados e detalhados fazendo com que a busca de projetos mais "baratos" implique muitas vezes na necessidade de adaptações durante a fase de execução da obra e futuramente em problemas de ordens funcional e estrutural (ARIVABENE, 2015).

A definição de conduta é a prescrição do trabalho a ser executado para resolver o problema, incluindo-se a definição sobre os meios (material, mão-de-obra e equipamentos) e a previsão das consequências em termos do desempenho final. Para definir a conduta, inicialmente é feito o prognóstico da situação, ou seja, são levantadas hipóteses da tendência de evolução futura do problema e as alternativas de intervenção (SILVEIRA NETO, 2005).

\subsubsection{Infiltrações, manchas, bolor ou mofo e eflorescências}

De acordo com Miotto (2010) apud Arivabene (2015), as manifestações patológicas encontradas com maiores frequências são: infiltrações, manchas, bolor ou mofo e eflorescências. Infiltração é o resultado de um processo onde a quantidade de água em contato com um substrato é tão grande que a mesma flui, ou até mesmo goteja, através desse substrato, dessa maneira, a água que fica aderida a esse substrato ocasionará o que chamamos de mancha; bolor ou mofo, é entendido como sendo a colonização por diversas populações de fungos filamentosos sobre os vários tipos de substrato, os quais formam manchas escuras indesejáveis em tonalidades preta, marrom e verde; eflorescências são formações salinas que ocorrem nas superfícies das paredes, trazidas de seu interior pela umidade.

\subsubsection{Concreto segregado}

O concreto é um produto composto por areia, pedra (seixo ou brita), cimento e água que quando preparado e lançado corretamente transforma-se em uma mistura homogênea, em que todas as pedras estão completamente envoltas pela argamassa (areia cimento e água). O lançamento deve ser feito de maneira uniforme por camadas com altura compatível ao adensamento previsto. No entanto, se ocorrer um erro de lançamento ou de adensamento as pedras se separam da 
argamassa formando um concreto cheio de vazios - permeável - que permite a passagem de água com facilidade (ARIVABENE, 2015).

Piancastelli (1997) apud Arivabene (2015) traz que esse processo de separação pode ser provocado, entre outras causas, por: lançamento livre de uma altura superior a 1 metro; concentração de armadura que impede a passagem da brita; vazamento da pasta de cimento através das fôrmas; má dosagem do concreto e o uso inadequado de vibradores. A segregação mais comum nas estruturas são os ninhos de concretagem que consistem em vazios deixados na massa de concreto devido à dificuldade de penetração do mesmo nas formas durante o processo de lançamento e adensamento (figura 1). Por outro lado, a segregação do concreto ocorre devido ao não envolvimento dos agregados pela pasta de cimento e a falta de homogeneidade dos componentes da mistura (SANTOS. 2014).

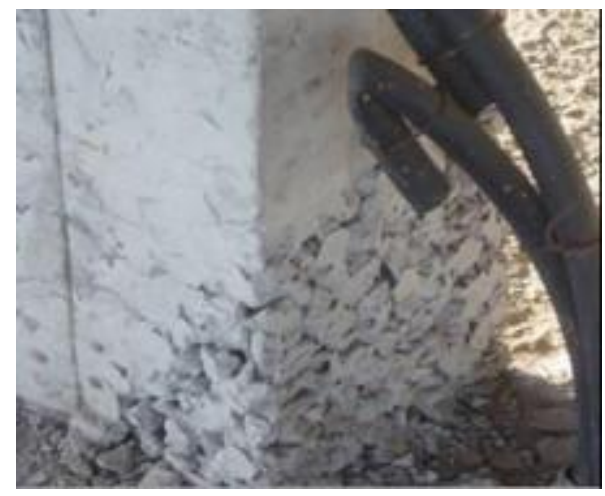

Figura 1: Ninhos e segregações no concreto.

\subsubsection{Fissuras}

De acordo com Souza e Ripper (1998) apud Arivabene (2015), as fissuras podem ser consideradas como manifestações patológicas características das estruturas de concreto, sendo o dano de ocorrência mais comum e aquele que, a par das deformações muito acentuadas, mais chama a atenção dos leigos, proprietários e usuários para o fato de que algo de anormal está a acontecer. A fissura é originada quando as tensões solicitantes são maiores do que a capacidade de resistência do material, assim, a fissura surge como forma de aliviar essas tensões.

A NBR 15.575:2013 - edificações habitacionais - desempenho parte 1: requisitos gerais, define fissura de um componente estrutural como sendo o seccionamento na superfície ou em toda seção transversal do componente, com abertura capilar, provocado por tensões normais ou tangenciais. As fissuras apresentam-se geralmente como estreitas e alongadas aberturas na superfície de um material. Usualmente são de gravidade menor e superficial. Na NBR 9575:2003, as fissura são caracterizadas como uma abertura ocasionada por ruptura de um material ou componente, essas inferiores ou iguais a $0,5 \mathrm{~mm}$ (figura 2 ).

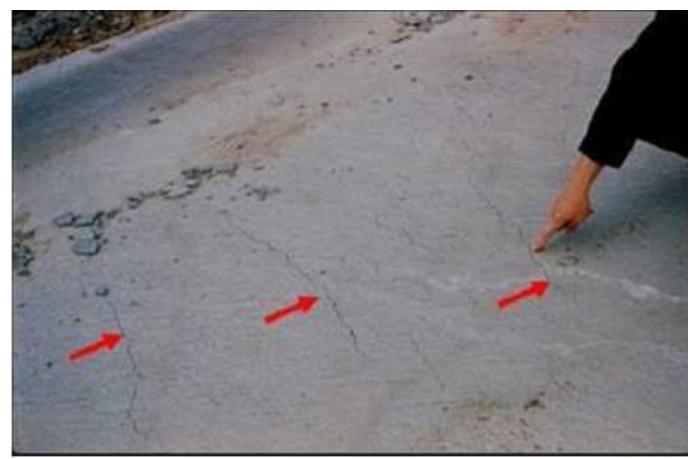

Figura 2: Fissura por retração plástica do concreto fresco.

\subsubsection{Trincas}

As trincas (figura 3) são aberturas mais profundas e acentuadas. O fator determinante para configurar uma trinca é a "separação entre as partes", ou seja, o material em que a trinca se encontra está separado em dois. Uma parede, por 
exemplo, estaria dividida em duas partes. Nesse contexto, as trincas se tornam muito mais perigosas do que as fissuras, pois apresentam ruptura dos elementos - como no caso mencionado da parede - e assim podem afetar a segurança dos componentes da estrutura das edificações. Ademais, de acordo com a NBR 9575:2003, as trincas são aberturas ocasionadas por ruptura de um material ou componente com abertura superior a $0,5 \mathrm{~mm}$ e inferior a $1,0 \mathrm{~mm}$, (ARIVABENE, 2015).

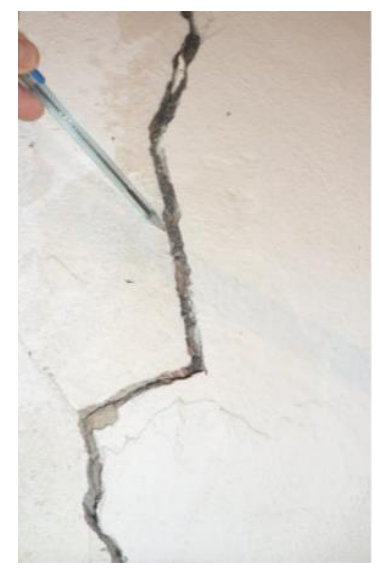

Figura 3: Trinca na alvenaria.

\subsubsection{Corrosão das armaduras}

Helene (2002) apud Arivabene (2015) em seu texto, define a corrosão das armaduras de concreto como um fenômeno de natureza eletroquímica que pode ser acelerado pela presença de agentes químicos externos ou internos ao concreto. No caso do concreto armado, o aço encontra-se no interior de um meio altamente alcalino no qual estaria protegido do processo de corrosão devido à presença de uma película protetora de caráter passivo, explica Cascudo (1997) apud Arivabene (2015). A alcalinidade no interior do concreto provém da fase líquida existente nos seus poros que contém hidroxilas oriundas da ionização dos hidróxidos de cálcio, sódio e potássio. Mesmo em idades avançadas o concreto continua propiciando um meio básico que protege a armadura do fenômeno da corrosão. Para Cascudo (1997) apud Arivabene (2015) os principais agentes agressivos (figura 4) que desencadeiam a corrosão das armaduras são: a ação dos íons cloretos (corrosão localizada por pite); a redução de ph do aço (corrosão generalizada $\rightarrow$ carbonatação) e a corrosão localizada sob tensão fraturante.

\section{Corrosão de armadura}

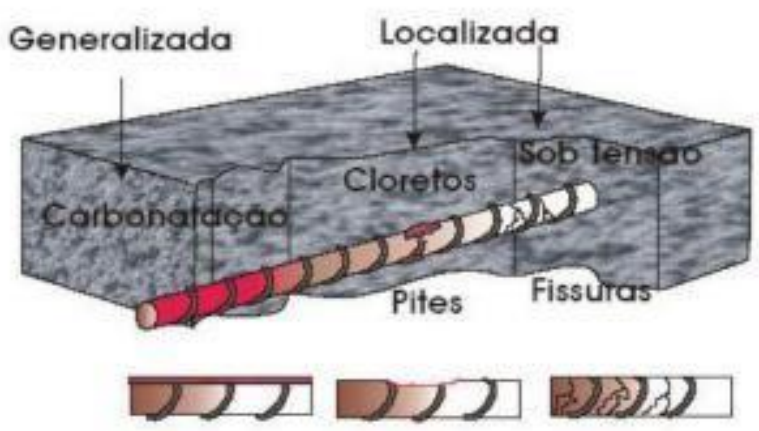

Figura 4: Tipos de corrosões e fatores que as provocam.

Em estruturas de concreto o cobrimento adequado das armaduras tem como função principal garantir proteção física e química para os vergalhões de aço. Falhas nessa barreira significam sujeitar as armaduras às agressões do meio ambiente, que induzem a corrosão do material e comprometem a capacidade de suporte de carga de toda a estrutura. Quanto maior for a espessura do cobrimento, maior tende a ser a proteção do aço. Entretanto, aumentar indiscriminadamente a camada de concreto não é recomendável, pois eleva o peso da estrutura, aumenta os custos e reduz a área útil construída. Neste caso, a saída é buscar um cobrimento ideal que garanta a proteção desejada sem excessos. Para isso, ABNT NBR 6118:2014 - projeto de estruturas de concreto, estabelece cobrimentos mínimos para vigas, pilares e lajes (AECWEB). 


\subsubsection{Descolamento cerâmico}

Fissuras, trincas, desplacamentos, irregularidades e eflorescências são manifestações patológicas comuns a revestimentos argamassados e cerâmicos. Contudo, aparecem com mais frequência em revestimentos argamassados, pois como citado por Bauer et al. (2015) apud Silva et al. (2016), as fachadas sofrem bastante agressão do meio externo, e no caso dos revestimentos argamassados, estes estão mais desprotegidos em relação aos cerâmicos. Além disso, o desplacamento do revestimento cerâmico pode ocorrer devido a aplicação irregular de argamassa no tardoz da peça, causando uma perda de aderência da cerâmica com a superfície.

\section{MÉTODOS}

Com base no estudo de Lichtenstein (1986), foram definidos os procedimentos a serem adotados para a realização deste trabalho. O procedimento consistiu em 3 etapas principais: (1) levantamento do maior número possível de subsídios para o entendimento do problema através de vistoria do local do histórico das edificações; (2) diagnóstico da situação para o entendimento completo dos fenômenos ocorridos e (3) definição de conduta a partir da escolha da alternativa de intervenção mais conveniente.

\subsection{Levantamento de subsídios}

Durante aproximadamente 30 dias, foram feitas visitas periódicas ao empreendimento, a fim de se realizar a primeira etapa do estudo que consistia em visitas in loco para coleta de dados. Durante as visitas foram observadas as mais diversas manifestações patológicas e falhas executivas nas edificações, dentre elas: nichos de concretagem, fissuras, trincas, descolamento de revestimento cerâmico, eflorescências, bolores, corrosão da armadura, etc. O levantamento foi feito através de fotografias e relatórios diários de todas as manifestações observadas e diálogos com os responsáveis pela obra, a fim de sanar os questionamentos ocorridos ao longo da visita.

\subsection{Diagnóstico da situação}

A partir das imagens produzidas durante as visitas, foram feitas análises minuciosas de todas as manifestações patológicas encontradas buscando definir o diagnóstico para cada uma delas.

\subsection{Definição de conduta}

Durante as visitas in loco foi possível observar os mais diversos tipos de manifestações patológicas. A partir do conhecimento teórico e de estudos realizados baseados nas manifestações encontradas foram definidas as condutas para solucionar e tornar apta as edificações para a sua futura entrega.

\section{RESULTADOS E DISCUSSÃO}

Neste capítulo será apresentado as manifestações patológicas encontradas no empreendimento e suas possíveis causas acompanhadas de suas soluções.

A figura 5 apresenta eflorescência nas paredes externas de concreto armado, um fenômeno muito comum, que ocorre quando a água infiltra nos poros do concreto dissolvendo os sais presentes no cimento e na cal, principalmente o hidróxido de cálcio. Esses sais são conduzidos até a superfície durante a evaporação da água através da percolação. Com a evaporação da água esses sais se cristalizam gerando manchas de cor clara. Na imagem pode-se observar o fenômeno.
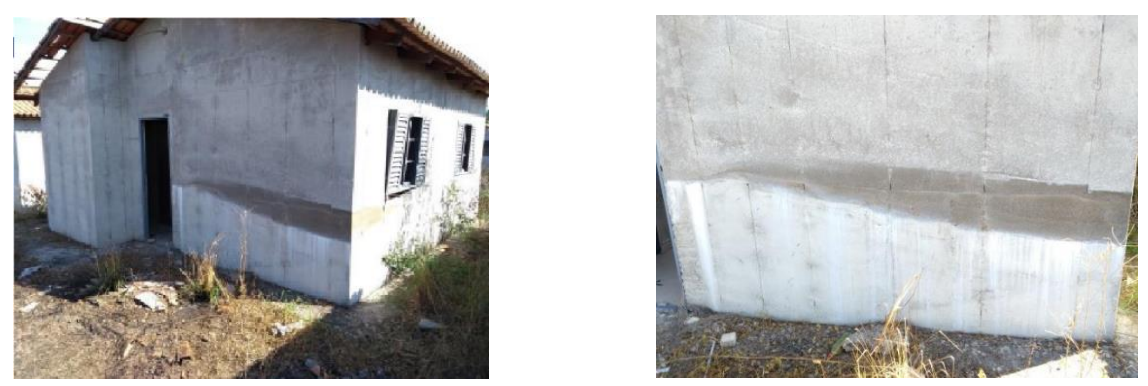

Figura 5: Eflorescência nas paredes externas de concreto armado. 
Causas prováveis: No empreendimento, após a concretagem as paredes de concreto armado sofreram exposição as adversidades climáticas durante vários meses até sua cobertura total, o que pode ter influenciado a aparição do fenômeno. Este fenômeno ocorre quando a umidade dissolve os sais de cálcio no concreto e migra para a superfície através da ação capilar. Quando estes sais atingem a superfície, eles reagem com $\mathrm{CO} 2$ presente no ar e ao evaporar deixa um depósito mineral que é carbonato de cálcio.

Solução: O método mais simples está em se dissolver os cristais com água sob pressão e remover com uma escova de cerdas naturais. Para executar este tipo de limpeza deve-se escolher um dia de sol para garantir a secagem do substrato por evaporação, caso contrário os sais irão se dissolver novamente.

A figura 6 apresenta nicho de concretagem com porosidade aberta e segregação dos materiais.
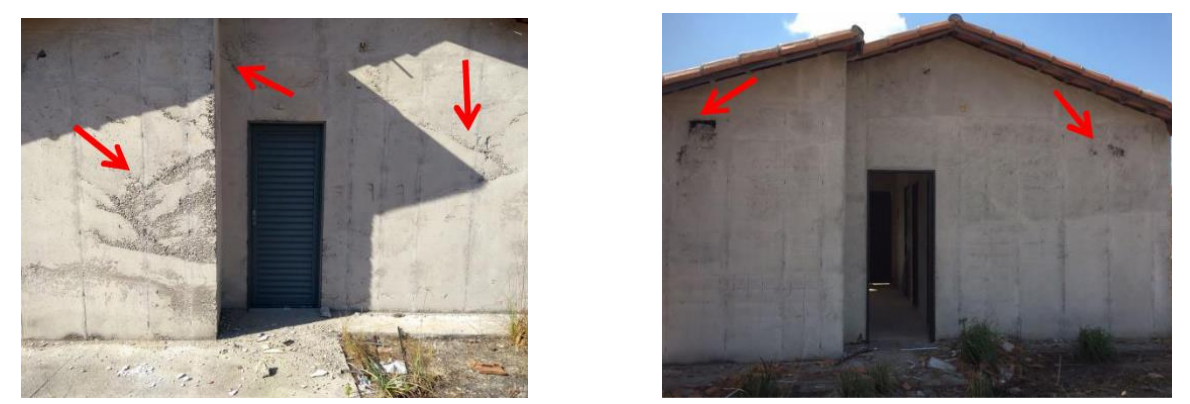

Figura 6: Nicho de concretagem

Causas prováveis: A vibração e o adensamento do concreto são atividades que se não forem executadas corretamente podem levar à formação de poros abertos no concreto e a irregularidades profundas que prejudicam o resultado estético ficando mais sucetíveis à penetração de agentes agressivos devido ao aumento dessa porosidade, causando os ninhos de concretagem.

Solução: Todo o concreto defeituoso removido deve ser substituído por um material de consistência plástica, podendo este material ser concreto convencional, argamassa, graute ou qualquer outro tipo de material de recuperação que adquira resistência compatível, tornando monolítico o elemento estrutural.

Nas figuras 7 e 8 foi possível verificar o descolamento parcial ou total do revestimento cerâmico no piso e nas paredes da edificação. A manifestação ocorreu em diversas unidades, tendo como característica principal o descolamento das placas da argamassa colante indicando aderência insuficiente ao substrato.
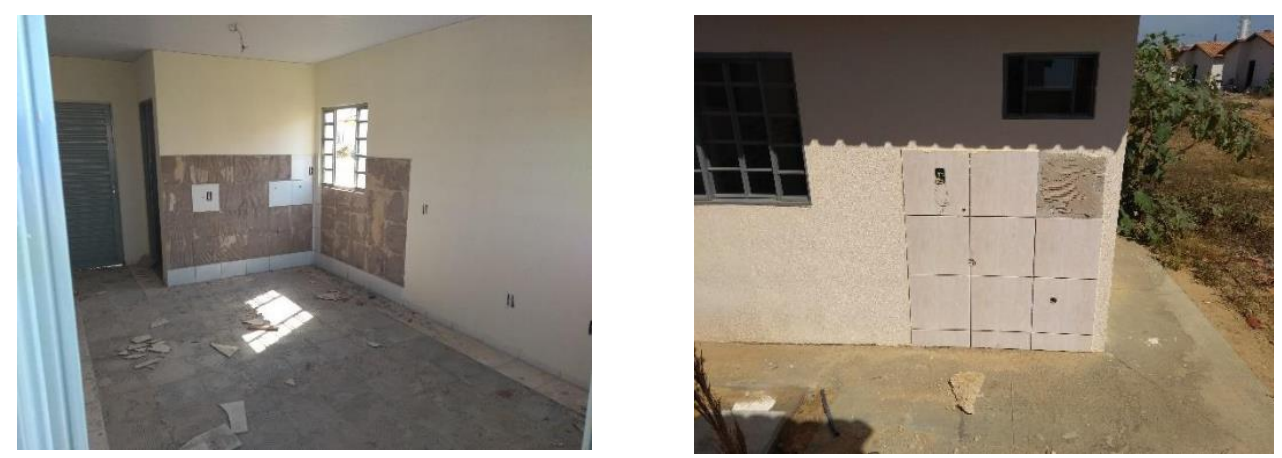

Figura 7: Descolamento de revestimento cerâmico da parede. 

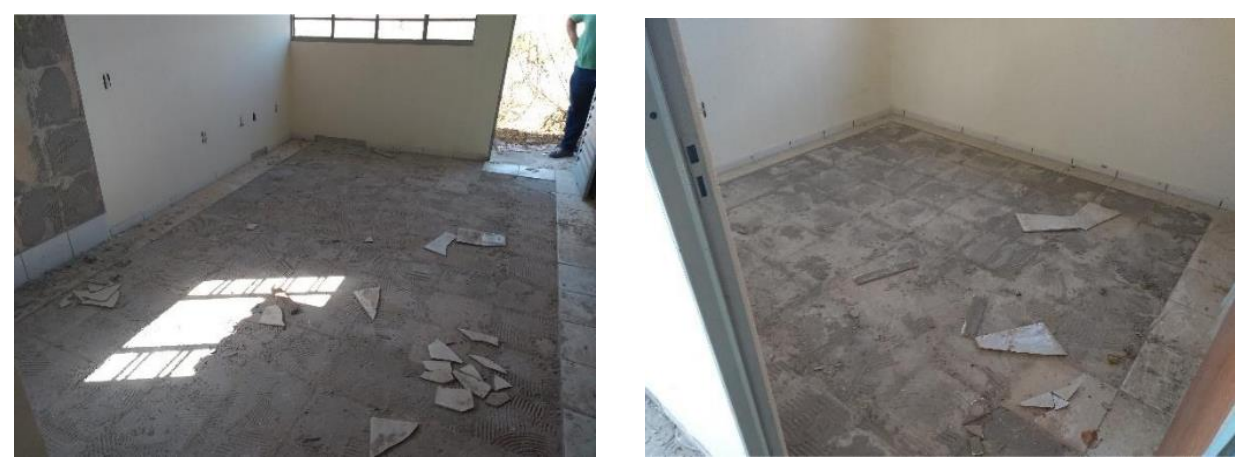

Figura 8: Descolamento de revestimento cerâmico do piso.

Causas prováveis: Foram identificados vários pontos de descolamento cerâmico nos quartos e na sala de estar que poderiam ter sidos ocasionados em virtude de molhagem deficiente da base comprometendo a hidratação do contrapiso, de uma aplicação inadequada da argamassa colante e de uma técnica de assentamento incorreta. Durante as visitas foi possível observar que cordões realizados na argamassa eram maiores que $8 \mathrm{~mm}$, tamanho comumente recomendado nos processos executivos, causando uma aderência ineficiente das placas com o substrato.

Solução: Limpar corretamente a superfície removendo sujeiras, pulverulências, eflorescências, bolor, etc. De acordo com a extensão da parede, pode-se utilizar broxa ou escova de fio de aço realizando a escovação seguida de lavagem com mangueira ou água pressurizada. Se existir mofo deve-se fazer a lavagem com água sanitária na proporção indicada pelo fabricante, seguida de enxágue com água limpa e verificar o estado do emboço onde será reassentada a cerâmica, realizando o ensaio de percussão. Se forem identificadas áreas com sonoridade cava, deve-se remover o emboço nesses locais e em seguida executá-lo novamente. Nas áreas onde o emboço estiver aderido, verificar o estado da sua superfície friccionando-a com uma escova de fio de aço. Em caso de desagregação, escovar e remover a camada desagregada até encontrar material firme e coeso. Na regularização do emboço - nos locais onde sua superfície foi parcialmente removida - deve ser preenchido com argamassa colante (a mesma usada para assentamento da cerâmica) não excedendo a espessura de $10 \mathrm{~mm}$. Realizado todos esses passos executa-se o revestimento com argamassa colante realizando cordões de até 8 $\mathrm{mm}$ na superfície do piso ou da parede.

Na figura 9 pode-se notar a presença de fissuras de retração em virtude do preenchimento com argamassa, uma vez que durante o processo de concretagem da edificação ocorreu uma falha na área da janela que posteriormente foi preenchida com argamassa de emboço que apresentou essa manifestação.
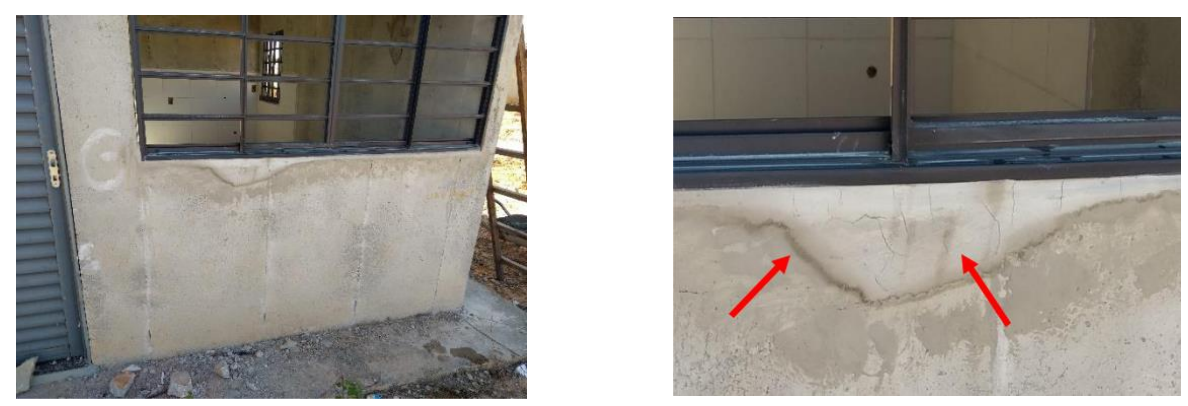

Figura 9: Fissura em argamassa de preenchimento.

Causas prováveis: Dentre as possíveis causas, pode ser citada a retração da argamassa que se caracteriza por uma diminuição do seu volume, resultante da perda de água excedente da mistura do material quando ele já se apresenta em estado sólido

Solução: O tratamento consiste em executar abertura de sulco em "V" e realizar o preenchimento com selante acrílico. Primeiramente, realiza-se a abertura do sulco sobre a fissura (utilizando a maquita ou espátula). Realizado o desbaste em torno de $10 \mathrm{~mm}$ para os dois lados é feita a remoção do acabamento da parede seguida da aplicação do selante acrílico, em seguida, têm-se o processo de secagem da fissura selada. Feito isso, caso a fissura seja passiva teremos a aplicação do impermeabilizante acrílico como etapa final do tratamento de fissuras. Porém, se constatado que a fissura é ativa aplica- 
se a segunda demão de impermeabilizante acrílico estruturado em tela de poliéster que tem função de evitar a movimentação desta patologia.

A figura 10 apresenta fissuras próximas as arestas vivas.
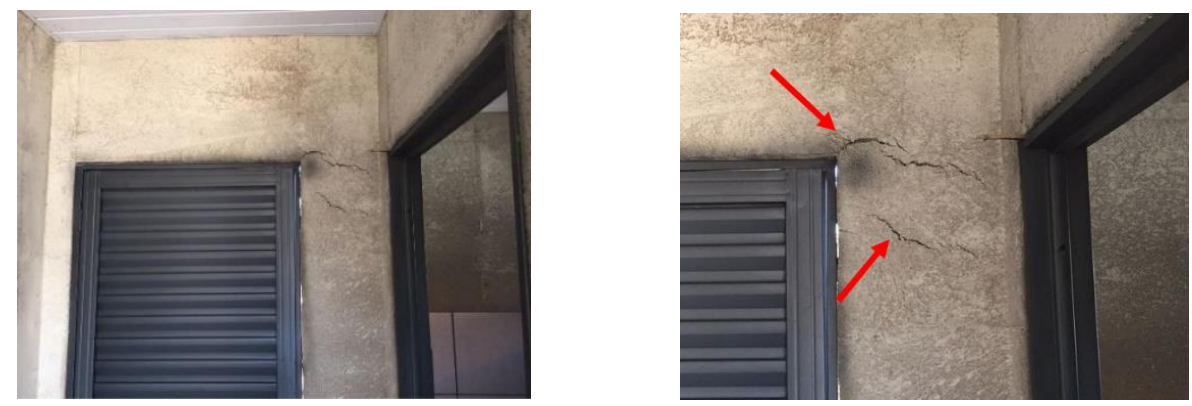

Figura 10: Fissura próximas as arestas vivas do concreto.

Causas prováveis: Podem ser associadas a essas fissuras o acúmulo de tensão nesses pontos, cujo o tratamento não foi executado da maneira correta a fim de absorver essas tensões.

Solução: Realizar retirada do material fissurado e executar o preenchimento com argamassa, graute ou qualquer material com resistência compatível a do concreto existente.

Na figura 11 observa-se fissuras horizontais e verticais equidistantes e pontos de exposição de armadura características de ineficiência do cobrimento, tornando a nata de proteção de armadura vulnerável ao surgimento de fissuras.
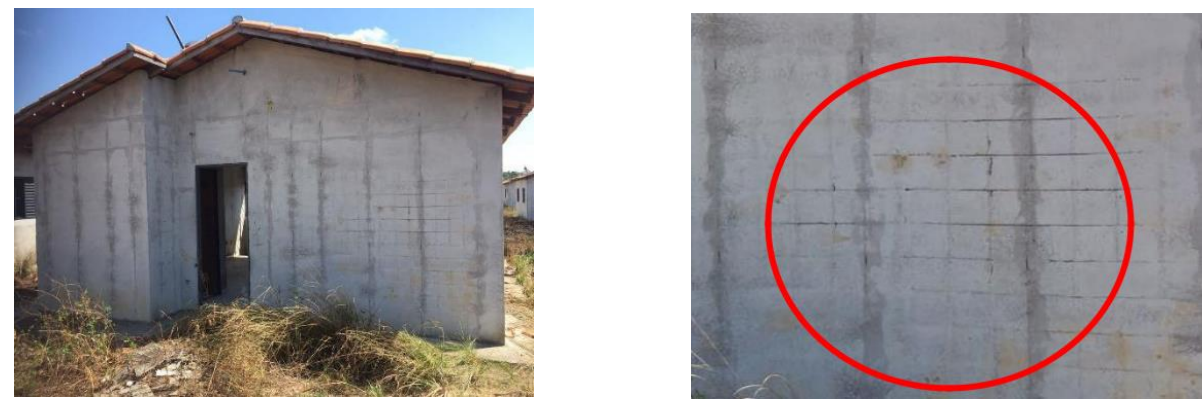

Figura 11: Cobrimento ineficiente e corrosão da armadura.

Causas prováveis: Cobrimento insuficiente da armadura pela argamassa do concreto.

Solução: Verificar o grau de corrosão das barras, caso a barra não tenha um grau de corrosão muito alto deve-se limpar a barra com o objetivo de recuperar a superfície. Além disso podem ser utilizadas tintas especias que protegem a estrutura a fim de evitar refazer o cobrimento das barras. Porém se a corrosão da armadura for muito acentuada, deve-se conversar com o projetista objetivando compreender se a armadura possui função estrutural e/ou para o içamento da peça, antes de tomar alguma providência.

\section{CONSIDERAÇÕES FINAIS}

A pesquisa teve como objetivo analisar as principais causas das manifestações patológicas que estão relacionadas ao sistema construtivo utilizado no objeto de estudo em questão - painéis de concreto armado moldados no local catalogando as manifestações patológicas encontradas no empreendimento e propondo suas respectivas soluções de acordo com as suas necessidades.

Durante a pesquisa, foram encontradas e discutidas diversas manifestações patológicas - que em grande parte poderiam ter sido evitadas - resultado de uma má execução da obra. A partir disto, é válido ressaltar a gravidade dos problemas apresentados no empreendimento, uma vez que os projetos foram executados de forma inadequada com falhas na execução e falta de fiscalização pela empresa responsável. Além disso, verificou-se que as manifestações patológicas, 


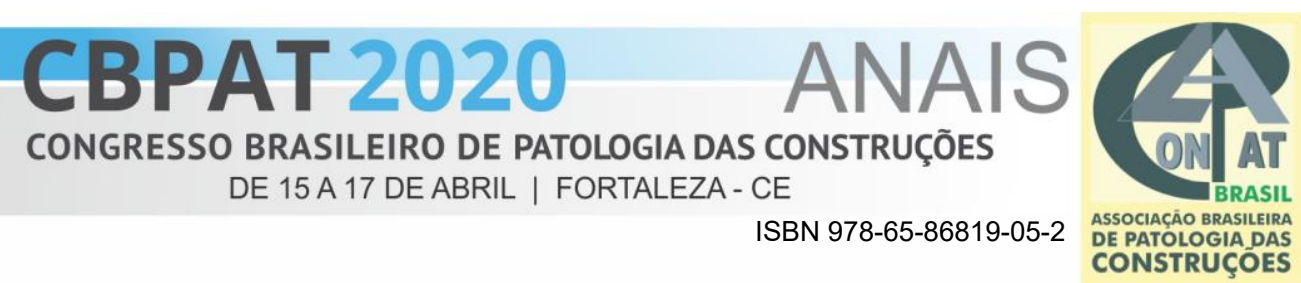

com maiores frequências, poderiam ter sido evitadas caso houvesse um controle de execução mais eficaz e uma fiscalização para averiguar se o concreto apresenta as características desejadas.

Conclui-se que para se usufruir das vantagens que o sistema construtivo oferece é necessário que não haja retrabalho e nem patologias, havendo ainda a necessidade de possuir uma equipe bem treinada e capacitada, tanto para execução como para acompanhamento e verificação dos serviços executados e dos que posteriormente serão executados. Dessa forma mantendo o tempo de execução inicialmente programado e assegurando que as manifestações patológicas tenham pouca ou nenhuma incidência.

Por fim, a partir das informações levantadas através da análise das manifestações patológicas verificadas na obra, nota-se a necessidade da implantação do controle na execução, objetivando a verificação dos materiais utilizados e sua correta aplicação; com a conferência da execução das paredes acompanhado dos projetos e o controle da concretagem. Desse modo, deve-se verificar os dados e as características do concreto atentando para o seu lançamento correto nas fôrmas e supervisionando na desforma, assim, promovendo um melhor rendimento na obra e as vantagens que o sistema construtivo possa oferecer. 


\section{REFERÊNCIAS}

ASSOCIAÇÃO BRASILEIRA DE NORMAS TÉCNICAS. NBR 6118: Projeto de estruturas de concreto Procedimentos. Rio de Janeiro, 2014.

ASSOCIAÇÃO BRASILEIRA DE NORMAS TÉCNICAS. NBR 15575-1: Edificações habitacionais — Desempenho Parte 1: Requisitos gerais. Rio de Janeiro, 2013.

ASSOCIAÇÃO BRASILEIRA DE NORMAS TÉCNICAS. NBR 9575: Impermeabilização: seleção e projeto. Rio de Janeiro, 2003.

ALVES, CLEBER DE O.; PEIXOTO, E. JOSÉ DOS S. Estudo Comparativo de Custo Entre Alvenaria Estrutural e Paredes De Concreto Armado Moldadas no Local com Fôrmas de Alumínio. Trabalho de Conclusão de Curso (Graduação em Engenharia Civil) - Universidade da Amazônia. Belém, Pará, 2011.

ARÊAS, D. M. Descrição do Processo Construtivo de Parede de Concreto Para Obra de Baixo Padrão. Trabalho de conclusão de curso (Graduação em Engenharia Civil) - Universidade Federal do Rio de Janeiro, Rio de Janeiro, 2013.

AZEVEDO, S.; RIBEIRO, L. C. Q. A produção da moradia nas grandes cidades: dinâmicas e impasses. In: RIBEIRO, L. C. Q.; AZEVEDO, S. A crise da moradia nas grandes cidades. Rio de Janeiro: Editora UFRJ, 1996.

ANDRADE, G. V. M Políticas habitacionais brasileiras: uma avaliação do programa minha casa minha vida em suas duas edições. Trabalho de conclusão de curso (Graduação em engenharia de produção) - Universidade Federal do Rio de Janeiro, Rio de Janeiro, 2012.

BOMFIM, M. A. M.; DUMÊT, T. B. Comparativo entre sistemas de vedações verticais: parede de concreto $x$ alvenaria estrutural. Inovação, Produtividade e Empreendedorismo na Engenharia Civil: melhores de 2013. Universidade Federal da Bahia, 2013.

BORGES, F. M. Sistema Construtivo de Habitação com Parede de Concreto. Projeto Final, Publicação n ${ }^{\circ}$ 137-2011, Curso de Engenharia Civil, Universidade Estadual de Goiás, Anápolis, GO, 98p. 2011.

BRASIL. Ministério das Cidades. Secretaria Nacional de Habitação. Déficit Habitacional no Brasil. Brasília: SNH, 2009. $129 \mathrm{p}$.

SANTOS, C. FREITAS DOS. Patologia de estruturas de concreto armado. Trabalho de conclusão de curso (Graduação em Engenharia Civil) - Universidade Federal De Santa Maria. Santa Maria, Rio Grade do Sul, 2014.

CÁNOVAS, M. F. Patologia e terapia do concreto armado. Tradução de Maria Celeste Marcondes, Carlos W. F. dos Santos, Beatriz Cannabrava. São Paulo: Pini, 1988.

CORSINI, R. Paredes Normatizadas. Revista Téchne. Jun .2012.

FUNDAÇÃO JOÃO PINHEIRO. Déficit habitacional no Brasil 2015: resultados preliminares / Fundação João Pinheiro. Disponível em: < http://fjp.mg.gov.br>. Acesso em: 9 dez. 2019b.

HELENE, P. R. L. Manual para Reparo, Reforço e Proteção de Estruturas de Concreto. São Paulo: Pini, 1997.

INSTITUTO DE PESQUISAS TECNOLOGICAS (IPT). Avaliação técnica de sistema construtivo integrado por paredes de concreto moldadas no local, para emprego em edificações de até cinco pavimentos. Disponível em: < https://www.ipt.br>. Acesso em: 5 dez. 1019b.

LICHTEnstein, N. B. Boletim Técnico 06/86: Patologia das Construções. Escola Politécnica da Universidade de São Paulo: São Paulo, 1986.

MACHADO, ARI DE P. Reforço de estruturas de concreto armado com fibras de carbono. São Paulo: Pini, 2002. 
MACHADO, A. A.; MARTINS, OSMAR DE C. Sistema construtivo de parede de concreto: considerações sobre os critérios de dimensionamento. Trabalho de conclusão de curso (Graduação em Engenharia Civil) - Universidade Tuiuti do Paraná. Curitiba, Paraná, 2015

MEDEIROS, V. QUADRO DE. Análise e mapeamento das manifestações patológicas vistoriadas pela seguradora em imóveis financiados pela Caixa Econômica Federal no Rio Grande do Sul em 1999 e 2000. Dissertação de mestrado (Mestrado profissionalizante em Engenharia) - Universidade Federal do Rio Grande do Sul. Porto Alegre, 2004.

MIOTTO, D. Estudo de caso de patologias observadas em edificação escolar estadual no município de Pato Branco - PR. Monografia (Especialização em Construção de Obras Públicas) - Universidade Federal do Paraná: Paraná. 2010.

MIOTTO, A. Avaliação das patologias no sistema construtivo em paredes de concreto moldadas no local para edifícios residenciais. Trabalho de conclusão de curso (Graduação em Engenharia Civil) - Universidade Tecnológica Federal do Paraná. Curitiba, Paraná, 2015.

MiSuRElli, H.; MASSUDA, C. Como Construir Paredes de Concreto, Revista Téchne, Edição 147. Jun. 2009.

OliveirA, F. C. C. Execução de Painéis Estruturais Pré-Moldados em Concreto Armado: Estudo de Caso. Trabalho de conclusão de curso (Graduação em Engenharia Civil) - Universidade Estadual de Feira de Santana, Bahia, 2009.

PIANCASTELli, É. M. Patologia, Recuperação e Reforço de Estruturas de Concreto Armado. Ed. Departamento de Estruturas da EEUFMG - 1997.

PIMENTA, C. L. Análise comparativa de custo de empreendimento de baixa renda entre os métodos construtivos em alvenaria estrutural e parede de concreto moldado in loco. Trabalho de conclusão de curso (Graduação em Engenharia Civil) - Universidade federal de Minas Gerais, Belo Horizonte, 2016.

SILVEIRA NETO, OMAR DA. Manifestações patológicas em condomínios habitacionais de interesse social do município de Porto Alegre: Levantamento e estudo sobre a recorrência. Dissertação de mestrado (Mestrado profissionalizante em Engenharia) - Universidade Federal do Rio Grande do Sul, Porto Alegre, 2005.

TUUTTI, K. Corrosion of steel in concrete. Stockholm, Swedish Cement and Concrete. Research Institute, 1982.

SANTOS, A. M. S. P. Município, descentralização e território. Rio de Janeiro: Forense, 2008.

SILVEIRA NETO, OMAR DA. Manifestações patológicas em condomínios habitacionais de interesse social do município de Porto Alegre: Levantamento e estudo sobre a recorrência. Dissertação de mestrado (Mestrado profissionalizante em Engenharia) - Universidade Federal do Rio Grande do Sul, Rio Grande do Sul, 2005.

SILVA, L.M.B. Desenvolvimento de um sistema especialista para diagnostico de fissuras em concreto Armado. Dissertação de mestrado (Mestrado profissionalizante em Engenharia) - Universidade Federal do Rio Grande do Sul, Rio Grande do Sul, 1996.

SILVA, A.; ALBUQUERQUE, G.; BELO, P.; SILVA, D. A problemática das manifestações patológicas nas fachadas de edifícios residenciais. Seminário de Patologia e Recuperação Estrutural. Universidade de Pernambuco, Pernambuco, 2016.

SOUZA, V. C.; RIPPER, T. Patologia, recuperação e reforço de estruturas de concreto. São Paulo: Pini, 1998. 255 p.

TRINDADE, D. S. Patologia em estruturas de concreto armado. Santa Maria, RS, Brasil 2015 14.p.

PINA, G. LOBO DE. Patologia nas habitações populares. Trabalho de conclusão de curso (Graduação em Engenharia Civil) - Universidade Federal do Rio de Janeiro. Rio de Janeiro, RJ, 2013. 